\title{
Adolescent Friendly Centre Service Provision Approach and Delivery of Health Information and Services for Peri- Urban Adolescents Enrolled in Reproductive Health Projects in Kisumu City, Kenya
}

\author{
Mutwii Mbithi, Abuya Isaac", Rambo Charles \\ University of Nairobi Kenya
}

DOI: $10.36348 /$ sjnhc.2020.v03i02.003

| Received: 05.02.2020 | Accepted: 13.02.2020 | Published: 14.02.2020

*Corresponding author: Dr. Isaac Abuya

\section{Abstract}

Adolescents in peri-urban settings are at increased risk of sexual and reproductive health challenges. Most peri-urban settings in developing countries are characterised by violence, illicit sex and drugs, abortions, limited access to quality health information and services among other challenges. Adolescent's friendly centres are believed to be one of the innovative strategies and approaches for delivering age and culturally appropriate sexual and reproductive health information and services for at risk and sexually active adolescents in peri-urban settings. Health based project organizations in peri-urban environments are routinely delivering health information and services for at-risk adolescents through 'adolescent's friendly centres'. However, few studies have assessed the relationship between adolescent friendly service provision approach and delivery of sexual and reproductive health information and services for sexually active peri-urban adolescents. The objective of this study was to assess the influence of adolescent friendly service provision approach on delivery of sexual and reproductive health information and services for sexually active peri-urban adolescents enrolled in reproductive health projects in peri-urban settings within Kisumu City. A cross sectional study design was used. The target population was 1299 adolescents, project managers and ASRH service providers. A sample size of 297 was computed using the Krecjie and Morgan sample estimation. A self-administered questionnaire was used. Descriptive and inferential data were analysed using SPSS. The descriptive statistics included frequencies, percentages, means and standard deviations. Inferential statistics included Pearson's correlation(r), co-efficient of determination $\left(\mathrm{R}^{2}\right)$, Anova Test ( $p$ value) and Beta coefficients $(\beta)$. There was statistically significant positive association between adolescent friendly centre approach and delivery of ASRHS $(r=304 \mathrm{p}<0.01)$. It is recommended that project based reproductive health organizations specializing in adolescent sexual and reproductive health projects should strengthen adolescent friendly centres to ensure sustained uptake of age and culturally appropriate sexual and reproductive health information and services for sexually active adolescents in peri-urban settings.

Keywords: Adolescent Friendly Centres Delivery Approach, Peri-Urban Adolescents, Health Information and Services, Demand Creation, Reproductive Health Projects, Peri-Urban Settings.

Copyright @ 2020: This is an open-access article distributed under the terms of the Creative Commons Attribution license which permits unrestricted use, distribution, and reproduction in any medium for non-commercial use (NonCommercial, or CC-BY-NC) provided the original author and source are credited.

\section{INTRODUCTION}

Adolescents in peri-urban settings are at increased risk of sexual and reproductive health challenges. Most peri-urban settings in developing countries are characterised by violence, illicit sex and drugs, limited access to quality health information and services [1-3]. Adolescent friendly centres are believed to be one of the innovative strategies and approaches for delivering age and culturally appropriate sexual and reproductive health information and services for at risk and sexually active adolescents in peri-urban settings. Despite the progress made in improving sexual and reproductive health services (SRHS) to the adolescents since the International Conference on Population and
Development (ICPD), young people are still vulnerable to poor and unfriendly sexual and reproductive health services. A large number of the adolescents lack access to comprehensive sexual and reproductive health information, education and services. This severely limits their ability to make informed decisions regarding their sexuality protect their health and stand up for their sexual and reproductive health rights (SRHR). Hierarchical and conservative ideas about the youth's autonomy and right to make decisions about their sexual and reproductive lives, restrict the young people's SRHR meaning that their voices go unheard. Social-cultural norms and values subordinate the adolescents and limit their reproductive rights, 
including access to contraception, safe and legal abortion and sexual rights [4].

As the young people pass through puberty and adolescence, new and emerging health concerns arise which has a great impact on their sexual and reproductive health. It is estimated that 3 percent of adolescents are HIV positive. The young women in this age group are more vulnerable to HIV infection than men of the same age [5]. Despite these challenges, many young people in need of SRH services are embarrassed to seek services because of fear of being seen by relatives or people who might identify them or their information being shared with family members [6].

Poverty has been a great barrier on the delivery of sexual and reproductive health services to the youth. Poverty is a cause, as well as a consequence of poor health and wellbeing of any group of people in the society more so the youth. In many developing countries, the governments do not have the capacity and resources to provide universal access in that there are no enough human resources that is trained doctors, nurses and midwives to provide services, supplies of drugs and contraceptives are often erratic, and some areas lack technical expertise to offer quality sexual and reproductive health services. The introduction of the cost component attached in this sexual and reproductive health services has prevented many poor people especially the adolescents from utilising SRH services. The adolescents living in poor households are more likely to be exposed to sexual coercion and engage in high-risk behaviours, such as transactional sex, nonconsensual sex, and sex with multiple partners than the adolescents who are financially stable or better off [7].

Asia and Pacific is the world's most populated region with 4.2 billion people and the region accounts for 60 percent of the world's adolescent population, amounting to approximately 750 million persons. While some progress has been made towards achieving universal access to sexual and reproductive health services in the region, the unmet need of SRH services still remain high. Approximately 38 percent of pregnancies in Asia are unintended, and sadly 21 percent end in abortion. The past 20 years have seen vast improvements in reducing teen's pregnancy; however, according to WHO about 30 percent of unsafe abortions occur among women younger than 20 years of age. HIV prevalence has been relatively stable in Asia; however, it is still remains a major concern in this region, especially among young people. This is because there is a wide gap in awareness of SRH programmes. Every year approximately 6 million adolescent girls in Asia become mothers, three quarters of whom are in South Asia [8].

Adolescents are the leading and frequent users of emergency contraception at Australian Family
Planning clinics [9].45percent of sexually active Australian high-school students do not use condoms consistently and 31 percent use condoms only as they are not aware of the other forms of contraceptives [10]. In rural and remote areas of Australia, young people's access to SRH services is linked to a number of factors including geography, socio-economic status, and gender and health education. The access to SRH is also affected by distance, expenses associated with the SRH services, scarcity of services and a smaller workforce who are expected to serve a large number of young people. Difficulties in accessing a range of contraceptive options by the young people may contribute to relatively high number of teenage pregnancies in rural communities. The Australian youths cites confidentiality concerns as a great hurdle in accessing SRH services.

United States teen pregnancy, birth, abortion and STIs rates are higher than those in most other developed countries [11]. The factors contributing to the high teen fertility and risky sexual behaviours include social-economic status, parental education, community and peer influences, self-esteem, access to education and school success among others [12]. Between 25 and 33 percent of adolescents forgo SRH and much other lack access [13]. Some of the factors hindering the adolescents from accessing or using SRH services include :lack of confidentiality-while 60 percent of adolescents seeking SRH services at family planning clinics do so with parental knowledge, one in five would use no contraceptive only if parental notification for prescription contraceptives were mandated [14], lack of access and utilization to preventive care-the low outpatient visits by adolescents put them at high risk for health complications, and high school drop outs are at even greater risk than their nondropout peers [15], lack of providers trained in SRH-out of the 195 accredited paediatric residency training programs in the US, only 27 have fellowship programs to train service providers in adolescent care lack of comprehensive sexuality education-fewer than half of all states require public schools to teach sex education and fewer than one-third require the curriculum to cover contraception [16].

In Tanzania the adolescents comprise 32 percent of the entire population [17]. These young people face several significant sexual and reproductive health challenges such as limited access to adolescent friendly services including information on growth, sexuality and family planning. As a result of this the young people are exposed to risky behaviours resulting to high STI and HIV prevalence, early pregnancies and vulnerability to delivery complications resulting in high rates of death and disability [18]. Socio-cultural factors leads to negative gender inequities in homes and the wider community, leading to disparities in access to SRH services, education and other key services [19]. A qualitative study by AMREF [20] in Tanzania focusing 
on the barriers to sexual and reproductive health services among young people revealed that a good number of health facilities do not have skilled services providers on SRH. It was also established that the SRH services were inaccessible due to lack of privacy, confidentiality, equipment and negative attitudes from services providers.

An assessment report of the national response to young people's sexual and reproductive health in Nigeria revealed major challenges affecting the delivery of SRH to the adolescents which include: lack of funding at the federal and state governments levels and no clear budgetary provision is made for programming on young people's SRH needs, the bulk of funding available for SRH programming is provided by international donors with strict policies, majority of the existing programmes are focused on young people in school and very few programmes target out-of-school adolescents, married adolescents, young people in difficult circumstances or those in rural areas, SRH supporting policies available on paper, but most are yet to be translated into meaningful programme interventions [21].The SRH needs of young people in Nigeria are often unattended to and have poor access to SRH services and information which results into risky sexual behaviours ,unsafe abortions, teenage pregnancies, drug abuse and HIV/AIDS infections [22].

Adolescents in Kenya, just like in other developing countries face a number of social, economic and health issues that affects their access to SRH services which are very critical in their lives. A report from FHI 360 and Ministry of Health [23] on adolescents and SRH in Kenya indicates several challenges at program and service delivery level .At program level the challenges highlighted includes; inadequate human and financial resources, programs not incorporating the social and cultural aspect into the interventions, inadequate distribution of SRH activities in the country, the emerging ICT platform has not been fully utilized by programs to reach adolescents with information; while the service delivery challenges includes; lack of adolescent friendly services (YFS), inadequate training and orientation of service providers to provide $\mathrm{SRH}$ services to the youth, awareness creation of available adolescents SRH services is inadequate, frequent shortage of commodities and supplies and lastly peer educators not being fully utilized. Population Council [24] cites that the Kenyan adolescents face a great setback in accessing SRH services due to low budget allocation on SRH, limited resources for better programming, inadequate physical infrastructure for provision of SRH services and inadequate reproductive health $(\mathrm{RH})$ information for youth.

Adolescents and young people in Nyanza region specifically in Kisumu like the rest of Kenya, encounter various SRH related problems resulting from low access to information and utilization of services. They are adversely affected because the area is the epicentre of HIV in the country [25]. Teenage pregnancy and motherhood is quite high where 15.4 percent of adolescent women aged 15-19 having had a live birth in Kisumu. The county has high unmet need for family planning that stands at 23.3 percent among currently married women in reproductive age with the young people worst hit [26]. A report by CSA Kenya [27] revealed that teachers and parents reported to have some problems that hinder them from discussing SRH issues effectively with the youth. Most teachers reported that they do not teach SRHR to students as the issues are not included in their curriculum, the subject is not examinable and in addition they rely on their own experiences to guide students. This was because their trainings do not capture SRH related to youth. On the other hand, parents also reported that they do not talk to their children because they don't take them seriously since they prefer getting SRH information from other sources.

In Kenya, the pendulum is steadily swinging back from focusing on risks of HIV/AIDS for adolescents to a broader approach or perspective to adolescents' development, including the pivotal issues related to sexual and reproductive health [28]. Many parties including donors, Non-Governmental Organizations, government agencies, programs and service providers are increasingly and steadily moving towards such a holistic approach to addressing adolescents' issues. The government agencies have expressed the need for better coordination of the multiple SRH projects being implemented by partners especially the NGOs [29]. The main program approaches used by most of the NGOs to reach the adolescents include peer education, edutainment, service delivery (including outreach services), adolescents support structures commonly referred to as adolescents centres, mass media, ICT, edusports, life skills education, mentorship, adult influencers, and advocacy for policy review or change [23].

Family Health Options Kenya (FHOK) is a Non-Governmental Organization with a long history of leadership in SRHR programs in Kenya and recognized for pioneering Family Planning (FP) services, Family Life Education for young people and providing integrated Clinic and Community based service delivery approaches especially through outreaches. In partnership with other organizations such as International Planned Parenthood Federation, Family Health International, and DANIDA among others, the organization is in pursuit of its core vision of ensuring that all people exercise their sexual reproductive rights and accessing quality sexual reproductive health services. The organization has a 5-year strategic plan running from 2016-2020 with 9 strategic areas of focus key amongst them being access to quality integrated 
SRH services and information, young people, finance and administration [30].

\section{LITERATURE REVIEW}

Adolescent Sexual and Reproductive Health Services Many of the challenges faced by the adolescents in search of services are related to the unwillingness of the society to adapt to the structurally changing position of adolescents in the modern world. In modern society, young people develop physically and emotionally at a rather young age, yet it several years later before they are ready to start a family. These young people simple need a friendly environment where they are free and feel comfortable to ask very deep and personal questions [31]. The main program approaches used by most of the NGOs to reach the adolescents include peer education, edutainment, service delivery (including outreach services), adolescents support structures commonly referred to as adolescents' centres, mass media, ICT, edusports, life skills education, mentorship, adult influencers, and advocacy for policy review or change [23]. The adolescents are great users of tools such as mobile phones, electronic diaries, i-phones and personal computers. On one hand they familiarise themselves with any emerging technology much quicker and more easily that the adults do; on the other hand, all these devices all so appealing to the young people, that they stand appreciated if not naively exploited. In addition to this, in low income countries, compared to traditional paper documents and land lines, the wireless connection as well as access to web provides and efficient platform for faster and easy access to information [31].

Clarke, Dick and Lewin [32] argue that Community outreach programs were initiated in the 1970 s by non-governmental organizations (NGOs) in response to the inadequate and intentionally inequitable public health care under the apartheid government. Although these outreach programmes have under gone diverse changes, many still remain active and very helpful to the community. In contrast to community outreach programmes in other countries like Iran and Brazil, where there are formalised and structured programmes, those in South Africa remain diverse and in most parts fragmented, unstructured and unregulated. These community outreach programmes are primarily run through NGO intermediaries. Many of the international and national NGOs and community based organisations developed in response to sexual reproductive health funding [33].

Edutainment uses drama, music or other communication formats that engage the emotions to inform audiences and change attitudes, behaviour, and social norms. The edutainment dramas can persuade because they show characteristics that change behaviour to improve lives. Stories have unique power and ability to describe people's behaviour and interactions, and their consequences when the audience members see that they could be in the same situation as the characters, stories can persuade them to change too including dropping of negative social norms [34]. Adolescent Friendly Centres are very important in provision of sexual and reproductive health services to the youth. This approach majorly involves access of adolescents friendly services in structures that tailor made for the youth, where they meet to get information on SRH and also get access to services in addition to engaging in various activities within the centre [35].

Schneider and Barron [36] in their study on the achievement of millennium development goals found that since 1994, South Africa has made remarkable investment in public health care through increased infrastructure, sexual reproductive health related programmatic interventions coupled with a rapid increase in utilisation of services provided by community health workers and non-governmental organizations majorly through outreach programmes. However, it was noted that despite these efforts and investments, the delivery of health services was still not up to expected citizens' standards. This was attributed to the growing demand of health services, and the failure to develop and implement an efficient district health system (DHS) to respond to the health needs of the local communities at the grass root level. The study further highlights the importance of the local nongovernmental organisation with capacity and resources to provide an enabling and supportive environment for conducting SRH services to the communities through outreach programs.

Young people across the globe experience high rates of HIV, Sexually Transmitted Infections (STIs), unplanned pregnancies and maternal morbidity and mortality. This is majorly owed to the fact that they (youth) cannot get quality SRH services due to its cost, accessibility and stigma that comes with it. Too many young people have limited information about SRH and normally face discrimination when they try to seek services. Alongside education, ensuring young people have access to a comprehensive package of SRH services delivered in a supportive and respectful environment is key to empowering young people and preventing poor health, thus contributing to the Sustainable Development Goal number three which seeks to ensure good health and wellbeing. The International Community has prioritised the introduction and scale up of 'adolescent friendly' approaches to education and service delivery to the youth. The approach is informed by the knowledge that young people are a diverse group with varying constraints, choices, and preferences and young people need to be at the centre of developing new innovative models and solutions for delivering SRH services [20].

A study in Zambia on vulnerability and sexual reproductive health among Zambian adolescents concluded that boys and girls lacked adequate and 
accurate information about sexual reproductive health services [37]. A study done by Motuma [38] on adolescent friendly services (YFS) utilization in Harar, Ethiopia concluded that most adolescents had positive attitude towards sexual reproductive health services but had poor knowledge on these services which exposed them to unwanted pregnancy, HIV/AIDS and STIs.

Bankole and Malarcher [39] reveals quite number of hurdles for young people who want or are in need of SRH services including high costs, lack of sex education, lack of information on SRH services, fear of discrimination, confidentiality concerns, legal and policy drawbacks. Young people may be disproportionately subjected to discriminatory by the service providers. Studies in Kenya, Nigeria, and Zambia indicated that one-half to two-thirds of service providers were unwilling to provide contraceptives to young people. The adolescents may be particularly reluctant to seek SRH services where extensive physical examination is performed if confidentiality and privacy are not assured [40].

\section{Adolescent Friendly Centre Delivery Approach}

Delivery of health services is the central process inside a health system. The manner in which this delivery is organized determines if the inputs lead the desired output of access to effective care and achievement of the health -related Sustainable Developments Goals (SDGs) [41]. Adolescent's sexual and reproductive health is a major developmental concern that every nation has paid a close attention. However, it is most profound in unindustrialized nations where the adolescent's population is growing fastest and over 13 million unintended births occur amongst adolescent girls each year [42]. Kenya has had a policy framework to support the provision of sexual and reproductive health services to youths since 2003.The adolescent reproductive health and development policy (ARHD) guidelines were finalized and released for use in July 2005. The policy critically adopted the recommendations of the WHO by directing that AFHS including those offered at adolescent friendly centres should be packaged in four aspects that is available, accessible, affordable and acceptable.

Adolescent reproductive health and development policy adopted two approaches, the targeted and integrated approach. In the targeted approach, services were offered for the adolescents alone and in environments that met only the needs of the adolescents and excluding other groups. Examples of such environments could be clinical, non-clinical or a combination of both, and evolved to be known as the Adolescent Friendly Centres. On the other hand, the integrated approach refers to a situation where youths received services as part of the public, but special arrangements were made to make the services more acceptable and attractive to them. However the evaluation of this policy found many weaknesses, including, poor engagement of stakeholders during implementation including the youth, poor and limited leadership, sub-optimal funding of the implementation of the policy, lack of political will, cultural and religious barriers to adolescent sexual and reproductive health services [43],implying that the implementation did not therefore meet the threshold of the WHO health service delivery framework-in terms of comprehensiveness, quality of care and effectiveness amongst other parameters.

Public health facilities have had a number of barriers such as lack of privacy and confidentiality as well as poor quality of services and the rudeness of the service providers which has hindered the young people from accessing services [10]. In response to this evidence, the World Health Organization developed the Youth-friendly health services: an agenda for change, which outlined several strategies for designing adolescent-friendly health services (AFHS), including the use of adolescent's friendly centres (YFCs) among other approaches. In 2006, a systematic review published by WHO of effectiveness of interventions to improve the utilization of adolescents sexual and reproductive health services in developing countries, found that arrangements aimed at making health services user-friendly and attractive to the adolescents had led to increase in the utilization of health services by the adolescents [41]. Onyando, Oluoch and Njuguna [43] in their study on the factors influencing effectiveness of adolescents friendly centres in Kenya found that: institutional factors such as flexible appointment times, structured referral system affects provision of SRH services, existing legal and policy frameworks act as barriers to the provision of certain SRH services. They recommended that there is need for the government and partners to: design centres that ensure integrated and innovative services; widely disseminate relevant policies and guidelines to the implementers and close supervision of service providers.

Where there is a safe and supportive environment, youths will be motivated to make, reinforce and maintain healthy choices. Adolescent friendly centres should be reachable, tolerable, unbiased, suitable and effective. However, observation has proved that even when clinics and other service programmes do not intend to prevent adolescent clients" access to their services, operational policies or clinic characteristics cab inadvertently serve to resource access [5]. A study by Godia [22] on sexual reproductive health service provision to young people in Kenya focusing on health service providers' experiences revealed that majority of health service providers (HSPs) were aware of the adolescent friendly service concept but not of the supporting national policies and guidelines. HSPs felt they lacked competency in providing SRH services to young people especially on counselling and interpersonal 
communication. HSPs were conservative when it comes to providing SRH services to young people particularly contraception. HSP reported being in a dilemma between personal feelings, cultural and religious values and beliefs and their wish to respect young people's rights to accessing SRH services.

\section{RESEARCH METHODOLOGY}

Research Design: This study relied on a crosssectional survey research design employing quantitative data collection and analysis method. Cross sectional design involve collection of data in more than once case at a single point in time. According to Babbie [21], cross sectional designs are designed to study some phenomenon by taking a cross section of it at one time. The design was the most appropriate for this study because it enabled the researcher to collect data within a relatively short span of time, and also in a cost effective manner.

Target Population: The target population was 1299 comprising of adolescents who are the beneficiaries of SRH services offered by Family Health Options Kenya through three major projects namely Get up Speak out (GUSO), Dance 4 Life (D4L) and Trigerise; and project staff (SRH service providers, project coordinators and project managers).

Table-1: Target Population

\begin{tabular}{|r|r|r|r|}
\hline $\begin{array}{c}\text { Name of } \\
\text { Project }\end{array}$ & $\begin{array}{c}\text { Number of Project } \\
\text { Staff }\end{array}$ & $\begin{array}{c}\text { Number of Adolescents } \\
\text { Enrolled in the Project }\end{array}$ & $\begin{array}{c}\text { Total Target } \\
\text { Population }\end{array}$ \\
\hline GUSO & 8 & 480 & 488 \\
\hline D4L & 10 & 440 & 450 \\
\hline Trigerise & 6 & 350 & 356 \\
\hline TOTAL & $\mathbf{3 4}$ & $\mathbf{1 2 7 0}$ & $\mathbf{1 2 9 9}$ \\
\hline
\end{tabular}

Sample Size: The sample size for this study was 297 drawn from a target population of 1299 using Krecjie and Morgan [44] sampling table.

Table-2: Proportionate Analysis of the Sample Size

\begin{tabular}{|l|l|l|l|l|}
\hline $\begin{array}{l}\text { Name of } \\
\text { Project }\end{array}$ & $\begin{array}{l}\text { Number of Project } \\
\text { Staff }\end{array}$ & $\begin{array}{l}\text { Number of Adolescents } \\
\text { Enrolled in the Project }\end{array}$ & $\begin{array}{l}\text { Total Target } \\
\text { Population }\end{array}$ & $\begin{array}{l}\text { Proportionate } \\
\text { Allocation }\end{array}$ \\
\hline GUSO & 8 & 480 & 488 & 112 \\
\hline D4L & 10 & 440 & 450 & 103 \\
\hline Trigerise & 6 & 350 & 356 & 82 \\
\hline & TOTAL & & $\mathbf{1 2 9 9}$ & $\mathbf{2 9 7}$ \\
\hline
\end{tabular}

Sampling Procedure: The sample size for this study was determined using Krecjie and Morgan [44] sampling table. Stratified random sampling was employed in selecting the respondents.

Research Instruments: The study used questionnaires which were administered to the adolescents, health service providers and project managers. The questionnaire had three sections. Section sought information on the demographic profile of the respondents. Section B and had five Likert scale statements on the independent and dependent variable. Section B sought information on adolescent friendly service provision approach, and Section C sought information on the delivery of adolescent sexual and reproductive health services.

Pilot Testing of Instruments: A pilot test was carried out in Kisumu West Sub-County where Marie Stopes International is implementing SRH programs. A ten percent of the sample size that is 29 respondents formed the group that was used for piloting. The research instrument was administered twice to the same group of respondents with an interval of 3 weeks during piloting. The results of the pilot test revealed consistency of responses.

The pilot test was conducted to check the reliability and validity of the questionnaire and also check their ethical appropriateness. According to Orodho [45] piloting addresses several questions including such as; are the questions measuring what they are supposed to? Do the respondents interpret all the questions the same way and do the questions provoke a response?

According to Mugenda and Mugenda [46], the purpose of pre-testing the instruments is to ensure that the items stated in the instruments are clearly stated and have the same meaning to all respondents and the respondents on which the instrument is pre-tested should not be part of the selected sample.

Validity of Research Instruments: A research instrument is said to be valid if it measures what it is supposed to measure and if the data collected through it actually represents the respondent's opinion [47]. It is the degree to which results obtained from the analysis 
of data actually represent phenomenon under study [48]. In this study, pilot testing was used as an important step in ensuring that the instrument was valid for the purpose of the study. Validity of the instruments was done with the help of the assigned supervisors who are experts in research to find out whether the questionnaire covers the conceptual domains of the research. The recommendations and suggestions were used to improve on the instruments to ensure maximum validity is achieved. Content validity was done to ensure that the items on the study are fairly representative of the entire domain the test seeks to measure, construct validity was adhered to by ensuring that the questions are phrased in the best way possible in terms of vagueness, clarity and instructions to guide then lastly face validity shall be done by a subjective and superficial assessment of whether the measurement procedure to use in the study appears to be a valid measure of a given variable or construct.

Reliability of Instruments: Mutea Rukwaru [49] argues that an instrument can be said to be reliable if it is stable. It does not change what or how it measures from time to time if the variable has not changed. Reliability is the extent to which a research project or a measuring tool would produce the same results if used repetitively on different occasion with the same objective of the study [50]. To ensure that the data collected was reliable, a comprehensive item analysis was done to ascertain that the questions asked are not ambiguous. An instrument is reliable if it produces the same results when applied to the same people severally. Pilot testing enabled the researcher to identify issues within the questionnaire which were addressed before the final study. Pre-testing enabled the researcher to estimate the time that it would take to administer each questionnaire. Kothari [51] advises that $10 \%$ of the sample is sufficient for pilot testing. Based on this advice, 30 questionnaires were pre-tested in Kisumu West Sub-County amongst project managers, service providers and adolescents who are beneficiaries of SRH programmes offered by Marie Stopes.

Data Collection Procedure: The researcher identified the research topic with the help of the supervisors and defended it before a panel of University of Nairobi experts. After incorporating the corrections, the researcher sought permission from the Ministry of Higher Education, the National Commission of Science, Technology and Innovation through the Board of Post Graduate Studies of the University of Nairobi to grant research permit and authority to conduct research in Kisumu Central Sub-County. Then the researcher visited the sample area and sought permission from the relevant authorities and management before embarking on data collection. The research assistants used in data collection were trained on the process of administering the questionnaires and on ethical issues. The researcher sought cooperation and maximised the respondents' time by first explaining the intent of the study and reassuring them about confidentiality of their feedback.

\section{Data Analysis Techniques}

Data analysis is the examining of what has been collected in a research and drawing deductions and references [52]. Data analysis seeks to fulfil research objectives and provide answers to the research questions. The data from this study was analysed quantitatively and descriptively using Statistical Programme for Social Sciences (SPSS). The descriptive statistics such as mean, frequency and percentages were used to analyse responses from the respondents on particular issues. Inferential statistics included Pearson's correlation( $r$ ), co-efficient of determination $\left(\mathrm{R}^{2}\right)$, Anova Test ( $\mathrm{p}$ value) and Beta coefficients $(\beta)$

Ethical Issues: Ethics is the standard of behaviour and practical procedures that a researcher is expected to follow [50]. The first ethical consideration was to abide by the procedure of entry to the community by seeking a permit from the National Commission of Science, Technology and Innovation to conduct the research. The researcher endured that there was informed consent from the respondents before administering the questionnaires.

The researcher assured the respondents that the information collected will be treated with utmost confidentiality and that it will only be used for academic purposes only and not passed to any other third party. To ensure full cooperation from the respondents, the researcher explained the significance of the study and their participation to them.

\section{RESULTS}

Questionnaire Return Rate: The study sought to establish the influence of project demand creation approaches on delivery of ASRHS.As it summarised under table 4.1, the sample size for this study was 297. However, thirty nine respondents opted not to participate in the study, hence reducing the number of the research participants to 258.The total number of questionnaires that were filled and returned were 258.According to Baruch and Holtom [53], the average level of response rate is 52.7 percent. The questionnaire return rate for this study was $86.9 \%$ compelling the researcher to proceed with the study.

Table-3: Questionnaire Return Rate

\begin{tabular}{|l|l|l|}
\hline Sample Size & Questionnaires filled & Return Rate Percentage \\
\hline 297 & 258 & $86.9 \%$ \\
\hline
\end{tabular}


Background Information of the Research Participant: The study sought information of demographic profiles of the research participants. Table 4 presents demographic profile data of the research participants.

Table-4: Distribution of Demographic Characteristics of the Respondents
\begin{tabular}{|l|l|c|c|}
\hline Respondents Profile & Categories & Frequency & Percentage \\
\hline Gender & Female & 122 & $47.3 \%$ \\
\cline { 2 - 4 } & Male & 136 & $52.7 \%$ \\
\cline { 2 - 4 } & Total & $\mathbf{2 5 8}$ & $\mathbf{1 0 0 . 0 \%}$ \\
\hline \multirow{5}{*}{ Respondent age } & $15-20$ yrs & 46 & $17.8 \%$ \\
\cline { 2 - 4 } & $21-30$ yrs & 165 & $64.0 \%$ \\
\cline { 2 - 4 } & $31-40$ yrs & 37 & $14.3 \%$ \\
\cline { 2 - 4 } & Above 40 yrs & 10 & $3.9 \%$ \\
\cline { 2 - 4 } & Total & $\mathbf{2 5 8}$ & $\mathbf{1 0 0 . 0 \%}$ \\
\hline \multirow{5}{*}{ Education level } & K.C.P.E & 8 & $3.1 \%$ \\
\cline { 2 - 4 } & K.C.S.E & 66 & $25.6 \%$ \\
\cline { 2 - 4 } & Diploma/Certificate & 119 & $46.1 \%$ \\
\cline { 2 - 4 } & Degree & 65 & $25.2 \%$ \\
\cline { 2 - 4 } & Total & $\mathbf{2 5 8}$ & $\mathbf{1 0 0 . 0 \%}$ \\
\hline \multirow{5}{*}{ Marital status } & Married & 57 & $22.1 \%$ \\
\cline { 2 - 4 } & Single & 196 & $76.0 \%$ \\
\cline { 2 - 4 } & Widowed & $\mathbf{2 5 8}$ & $\mathbf{1 0 0 . 0 \%}$ \\
\cline { 2 - 4 } & Widower & & $0.9 \%$ \\
\cline { 2 - 4 } & Total & 0 & \\
\hline
\end{tabular}

Table 4 presents the distribution of demographic characteristics of respondents. The demographic questionnaire for delivery of ASRHS sought information on gender of the respondents, their age bracket, highest educational qualification and marital status. Out of the 258 respondents, 122(47.3\%) were female and $136(52.7 \%)$ were male suggesting that majority of those interviewed were male. It is also an indication that Family Health Options Kenya has projects not only benefit the girl child but also the boy child.

On the age bracket results shows that majority of the respondents who filled in the questionnaire were $165(64 \%)$ aged between 21-30 years; $46(17.8 \%)$ aged between 15-20 years; 37 (14.3\%) aged between 31-40 years and $10(3.9 \%)$ above 40 years. This is an indication the biggest consumers of adolescent sexual and reproductive health services are adolescents aged between 21-30 years while the least consumers are those that are above 40 years of age.

Highest educational qualification results indicated that $119(46.1 \%)$ were diploma holders,
66(25.6\%) secondary school certificate holders, $65 \%($ $25.2 \%)$ were degree holders and $8(3.1 \%)$ primary school certificate holders. This indicates that Kisumu Central Sub-County has embraced formal education as the figures shows relatively high literacy level among the respondents. Despite the relatively high levels of education, delivery of ASRHS is low suggesting that there are other factors influencing delivery of ASRHS. The results on marital status indicated that out of 258 respondents, $196(76 \%)$ were single, 57(22.1\%) were married, 5(1.9\%) were widowed and none of the respondents was a widower. This indicates majority of the beneficiaries of the projects implemented by FHOK in Kisumu Central-Sub County are the single adolescents suggesting that the singles have the highest appetite for ASRHS.

\section{Delivery of Adolescent Sexual and Reproductive Health Services}

The dependent variable of this study was the delivery of ASRHS. The descriptive statistics which comprises of percentages, mean and statistics is shown under table 5. 
Table-5: Descriptive Analysis of Delivery of Adolescent Sexual and Reproductive Health Services

\begin{tabular}{|c|c|c|c|c|c|c|c|c|c|}
\hline Item & Statement & SD & D & $\mathbf{N}$ & A & SA & Total & Mean & $\begin{array}{c}\text { Std. } \\
\text { Deviation }\end{array}$ \\
\hline \multirow[t]{2}{*}{ DASRH-1 } & \multirow[b]{2}{*}{$\begin{array}{c}\text { Project } \\
\text { enhances } \\
\text { adolescents' } \\
\text { access to } \\
\text { SRH } \\
\text { information }\end{array}$} & 1 & 1 & 6 & 109 & 141 & 258 & 4.50 & 0.606 \\
\hline & & $.4 \%$ & $.4 \%$ & $2.3 \%$ & $42.2 \%$ & $54.7 \%$ & $100.0 \%$ & & \\
\hline \multirow[t]{2}{*}{ DASRH-2 } & \multirow{2}{*}{$\begin{array}{c}\text { Project } \\
\text { enhances } \\
\text { adolescents' } \\
\text { access to } \\
\text { SRH services } \\
\end{array}$} & 1 & 5 & 12 & 115 & 125 & 258 & 4.39 & 0.704 \\
\hline & & $.4 \%$ & $1.9 \%$ & $4.7 \%$ & $44.6 \%$ & $48.4 \%$ & $100.0 \%$ & & \\
\hline \multirow[t]{2}{*}{ DASRH-3 } & \multirow[b]{2}{*}{$\begin{array}{c}\text { Project } \\
\text { promotes } \\
\text { adolescents' } \\
\text { informed } \\
\text { choices on } \\
\text { SRH } \\
\text { information } \\
\text { and services }\end{array}$} & 1 & 1 & 12 & 133 & 111 & 258 & 4.36 & 0.629 \\
\hline & & $.4 \%$ & $.4 \%$ & $4.7 \%$ & $51.6 \%$ & $43.0 \%$ & $100.0 \%$ & & \\
\hline \multirow[t]{2}{*}{ DASRH-4 } & \multirow[b]{2}{*}{$\begin{array}{l}\text { Project } \\
\text { provides } \\
\text { adolescents } \\
\text { friendly } \\
\text { information } \\
\text { and services }\end{array}$} & 1 & 3 & 21 & 107 & 125 & 257 & 4.37 & 0.718 \\
\hline & & $.4 \%$ & $1.2 \%$ & $8.2 \%$ & $41.6 \%$ & $48.6 \%$ & $100.0 \%$ & & \\
\hline \multirow[t]{2}{*}{ DASRH-5 } & \multirow{2}{*}{$\begin{array}{c}\text { Project } \\
\text { promotes safe } \\
\text { adolescent } \\
\text { SRH services }\end{array}$} & 5 & 8 & 10 & 109 & 126 & 258 & 4.33 & 0.848 \\
\hline & & $1.9 \%$ & $3.1 \%$ & $3.9 \%$ & $42.2 \%$ & $48.8 \%$ & $100.0 \%$ & & \\
\hline \multicolumn{8}{|c|}{ in and Standar } & 4.39 & 0.701 \\
\hline
\end{tabular}

Table 5 presents the descriptive statistics on the perspectives of the research participants on the delivery of adolescent sexual and reproductive health services.

Item DASRH1 sought to establish to what extend project enhances adolescents' access to SRH information. Out of 258 respondents who responded to the item, $141(54.7 \%)$ strongly agreed, 109 (42.2\%) agreed, $6(2.3 \%)$ were neutral, $1(0.4 \%)$ disagreed and also 1(0.4) strongly disagreed. Item DASRH1 had a positive influence on the delivery of adolescent sexual and reproductive health services. This is showed by the item having a mean of 4.50 which is higher than the composite mean of 4.39 .

Item DASRH2 sought to establish to what extend does project enhances adolescents' access to SRH information. Out of the 258 respondents who responded to the item $125(48.4 \%)$ strongly agreed, $115(44.6 \%)$ agreed, $12(4.7 \%)$ were neutral, 5(1.9\%) disagreed and $1(0.4 \%)$ strongly disagreed. Item DASRH2 had a positive influence on the delivery of adolescent sexual and reproductive health services. This is showed by the item having a mean of 4.39 equivalents to the composite mean of 4.39 .
Item DASRH3 sought to establish to what extend adolescent sexual and reproductive health project promotes adolescents' informed choices on SRH information and services. Out of the 258 respondents who responded to the item $133(51.6 \%)$ agreed, $111(43 \%)$ strongly agreed, $12(4.7 \%)$ were neutral, $1(0.4 \%)$ disagreed and also $1(0.4 \%)$ strongly disagreed. Item DASRH3 had a negative influence on the delivery of adolescent sexual and reproductive health services. This is showed by the item having a mean of 4.36 which is lower than the composite mean of 4.39 .

Item DASRH4 sought to establish to what extend adolescent sexual and reproductive health project provides adolescent friendly information and services. Out of the 258 respondents who responded to the item, $125(48.6 \%)$ strongly agreed, 107(41.6\%) agreed, $21(8.2 \%)$ were neutral,3(1.2\%) disagreed and also $1(.4 \%)$ strongly disagreed. Item DASRH4 had a negative influence on the delivery of adolescent sexual and reproductive health services. This is showed by the item having a mean of 4.37 which is lower than the composite mean of 4.39 . 
Item DASRH5 sought to establish to what extend adolescent sexual and reproductive health project promotes safe adolescents SRH services. Out of the 258 respondents who responded to the item, $126(48.8 \%)$ strongly agreed, 109(42.2\%) agreed, 10 $(3.9 \%)$ were neutral,8(3.1\%) disagreed and also 5 (1.9\%) strongly disagreed. Item DASRH5 had a negative influence on the delivery of adolescent sexual and reproductive health services. This is showed by the item having a mean of 4.33 which is lower than the composite mean of 4.39 .

\section{Descriptive Analysis of Adolescents Friendly Centre Approach}

The study sought to establish the frequencies, percentages, means and standard deviation on adolescent friendly centre approach. The analysis is shown under table 6 .

Table-6: Descriptive Statistics on Entertainment Education Approach

\begin{tabular}{|c|c|c|c|c|c|c|c|c|c|}
\hline Items & Statements & $\mathbf{S A}$ & D & $\mathbf{N}$ & A & SA & Total & Mean & $\begin{array}{c}\text { Std. } \\
\text { Deviation }\end{array}$ \\
\hline \multirow{2}{*}{ YFCA1 } & \multirow{2}{*}{$\begin{array}{l}\text { Adolescent friendly centre } \\
\text { enhances confidentiality }\end{array}$} & 2 & 2 & 5 & 109 & 140 & 258 & 4.48 & 0.573 \\
\hline & & $.8 \%$ & $.8 \%$ & $1.9 \%$ & $42.2 \%$ & $54.3 \%$ & $100.0 \%$ & & \\
\hline \multirow[t]{2}{*}{ YFCA2 } & \multirow{2}{*}{$\begin{array}{l}\text { Adolescent friendly centre } \\
\text { promotes privacy }\end{array}$} & 0 & 1 & 7 & 118 & 132 & 258 & 4.13 & 0.965 \\
\hline & & $0.0 \%$ & $.4 \%$ & $2.7 \%$ & $45.7 \%$ & $51.2 \%$ & $100.0 \%$ & & \\
\hline \multirow[t]{2}{*}{ YFCA3 } & \multirow{2}{*}{$\begin{array}{l}\text { Adolescents actively } \\
\text { participate in adolescent } \\
\text { friendly centre }\end{array}$} & 9 & 13 & 12 & 125 & 99 & 258 & 4.37 & 0.754 \\
\hline & & $3.5 \%$ & $5.0 \%$ & $4.7 \%$ & $48.4 \%$ & $38.4 \%$ & $100.0 \%$ & & \\
\hline \multirow[t]{2}{*}{ YFCA4 } & \multirow{2}{*}{$\begin{array}{l}\text { Sexual and reproductive } \\
\text { health services are affordable }\end{array}$} & 1 & 6 & 19 & 103 & 129 & 258 & 4.39 & 0.826 \\
\hline & & $.4 \%$ & $2.3 \%$ & $7.4 \%$ & $39.9 \%$ & $50.0 \%$ & $100.0 \%$ & & \\
\hline \multirow[t]{2}{*}{ YFCA5 } & \multirow{2}{*}{$\begin{array}{l}\text { Adolescent centre is } \\
\text { conveniently located and } \\
\text { easily accessible }\end{array}$} & 1 & 14 & 9 & 93 & 141 & 258 & 4.50 & 0.644 \\
\hline & & $.4 \%$ & $5.4 \%$ & $3.5 \%$ & $36.0 \%$ & $54.7 \%$ & $100.0 \%$ & & \\
\hline \multicolumn{8}{|c|}{ Composite Mean and Standard Deviation } & 4.37 & 0.752 \\
\hline
\end{tabular}

Table 5 presents the descriptive statistics on the perspective of the research participants on the influence of adolescent friendly centre approach on delivery of adolescent sexual and reproductive health services.

Item YFCA1 sought to establish to what extent adolescent friendly centre enhances confidentiality of adolescents' sexual and reproductive health information. Out of the 258 respondents who responded to the item, $140(54.3 \%)$ strongly agreed, $109(42.2 \%)$ agreed and $5(1.9 \%)$ were neutral, $2(0.8 \%)$ disagreed and $2(0.8 \%)$ strongly disagreed. Item YFCA1 had a positive influence on the delivery of adolescent sexual and reproductive health services. This is showed by the item having a mean of 4.48 which is higher than the composite mean of 4.37 .

ItemYFCA2 sought to establish to what extent adolescent friendly centre promotes privacy of sexual and reproductive health services provided to adolescents. Out of the 258 respondents who responded to the item, $132(51.2 \%)$ strongly agreed, 118(45.7\%) agreed, $7(2.7 \%)$ were neutral and $1(0.4 \%)$ disagreed. Item YFCA2 had a negative influence on the delivery of adolescent sexual and reproductive health services. This is showed by the item having a mean of 4.13 which is lower than the composite mean of 4.37 .
Item YFCA3 sought to establish to what extent adolescents participate in the planning of services at the adolescent friendly centre. Out of the 258 respondents who responded to the item, 125 (48.4\%) agreed, 99(38.4\%) strongly agreed, 13(5.0\%) disagreed, $12(4.7 \%)$ were neutral and $9(3.5 \%)$ strongly disagreed. Item YFCA3 had a positive influence on the delivery of adolescent sexual and reproductive health services. This is showed by the item having a mean of 4.37 which is equal to the composite mean of 4.37 .

Item YFCA4 sought to establish to what extent sexual and reproductive health services provided at the adolescent centre are affordable. Out of the 258 respondents who responded to the item, $129(50.0 \%)$ strongly agreed, 103(39.9\%) agreed, 19(7.4\%) were neutral, $6(2.3 \%)$ disagreed and $1(0.4 \%)$ strongly disagreed. Item YFCA4 had a positive influence on the delivery of adolescent sexual and reproductive health services. This is showed by the item having a mean of 4.39 which is higher than the composite mean of 4.37 .

Item YFCA5 sought to establish to what extent adolescent friendly centre is conveniently located and easily accessible. Out of the 258 respondents who responded to the item, 141(54.7\%) strongly agreed, 93(36.0\%) agreed, 14(5.4\%) disagreed, $9(3.5 \%)$ were neutral and $1(0.4 \%)$ strongly 
disagreed. Item YFCA5 had a positive influence on the delivery of adolescent sexual and reproductive health services. This is showed by the item having a mean of 4.50 which is higher than the composite mean of 4.37 .

\section{Correlation Analysis}

Pearson product moment correlation coefficient was used to establish the existence or nonexistence of significant relationship as well the degree or strength of association between entertainment education approach and delivery of adolescent sexual and reproductive health services, based on the perspectives of research participants.

Table-7: Correlations Statistics

\begin{tabular}{|l|l|l|l|}
\hline \multicolumn{2}{|c|}{} & $\begin{array}{l}\text { Adolescent Friendly Centre } \\
\text { Approach }\end{array}$ & $\begin{array}{l}\text { Delivery of } \\
\text { ASRHS }\end{array}$ \\
\hline $\begin{array}{l}\text { Adolescent Friendly Centre } \\
\text { Approach }\end{array}$ & $\begin{array}{l}\text { Pearson } \\
\text { Correlation }\end{array}$ & 1 & $.304^{* *}$ \\
\cline { 2 - 4 } & Sig. (2-tailed) & & .000 \\
\cline { 2 - 4 } & $\mathrm{N}$ & 258 & 258 \\
\hline \multirow{3}{*}{ Delivery of ASRHS } & $\begin{array}{l}\text { Pearson } \\
\text { Correlation }\end{array}$ & $.304^{* *}$ & 1 \\
\cline { 2 - 4 } & Sig. (2-tailed) & .000 & 258 \\
\cline { 2 - 4 } & $\mathrm{N}$ & 258 & \\
\hline **. Correlation is significant at the 0.01 level (2-tailed). & \\
\hline
\end{tabular}

Table 7 presents correlations statistics on adolescent friendly centre approach and delivery of ASRHS. The analysis shows a weak correlation between independent variable adolescent friendly centre approach and the dependent variable delivery of ASRHS with $r=0.304 p<0.01$. The findings showed that there was statistical significance between adolescent friendly centre approach and delivery of ASRHS. The findings are consistent with the findings of studies reviewed under literature review that found significant relationship between adolescent friendly centre approach and delivery of ASRHS [43].

\section{Regression Analysis}

To find the amount of variation in delivery of adolescent sexual and reproductive health services, which explains its association with adolescent friendly centre approach, the coefficient of determination $\left(\mathrm{R}^{2}\right)$ was computed. The coefficient was also used to help in understanding or explaining the amount of variation in the delivery of adolescent sexual and reproductive health services.

Table-8: A model Summary

\begin{tabular}{|l|c|c|c|c|}
\hline Model & R & R Square & $\begin{array}{c}\text { Adjusted R } \\
\text { Square }\end{array}$ & $\begin{array}{c}\text { Std. Error of } \\
\text { the Estimate }\end{array}$ \\
\hline 1 & $.304^{\mathrm{a}}$ & .093 & .089 & .39141 \\
\hline a. Predictors: (Constant), Adolescent Friendly Centre Approach \\
\hline
\end{tabular}

Table 8 is the model summary of the association between adolescent friendly centre approach and delivery of adolescent sexual and reproductive health services. According to the model summary, the $r$ value stands at 0.304 which implies that the model predicts the delivery of ASRHS but to a weak degree. This is evident from the $\mathrm{R}^{2}$ value which stand at 0.093 (or $9.3 \%$ ) which indicates the proportion of variance in delivery of ASRHS that adolescent's friendly centre can influence. When extrapolating this discovery beyond the sample to the entire population, the $\mathrm{R}^{2}$ value stands at $8.9 \%$. The findings of the summary model are consistent with the findings of studies reviewed under the literature review that found significant relationship between adolescent friendly centre approach and delivery of ASRHS [50].

Table-9: ANOVA Test

\begin{tabular}{|l|l|r|r|r|r|r|}
\hline \multicolumn{2}{|l|}{ Model } & $\begin{array}{c}\text { Sum of } \\
\text { Squares }\end{array}$ & \multicolumn{1}{c|}{ df } & $\begin{array}{c}\text { Mean } \\
\text { Square }\end{array}$ & F & Sig. \\
\hline \multirow{3}{*}{1} & Regression & 4.001 & 1 & 4.001 & 26.115 & $.000^{\mathrm{b}}$ \\
\cline { 2 - 7 } & Residual & 39.220 & 256 & .153 & & \\
\cline { 2 - 7 } & Total & 43.221 & 257 & & & \\
\hline
\end{tabular}


From the above analysis of the Anova, it is evident that the significance of the relationship between the adolescent friendly centre approach and delivery of ASRHS or the $\mathrm{p}$ value stands at 0.000 , which is less than 0.05. This compels the researcher to reject the null hypothesis that 'there is no significant relationship between adolescent friendly centre approach and delivery of adolescent sexual and reproductive health services'. Hence, the researcher concluded that there was a significant relationship between adolescent friendly centre approach and delivery of ASRHS which is in consistent with the studies reviewed under literature review that found significant relationship between adolescent friendly centre approach and delivery of ASRHS [5].

Table-10: Regression Coefficients

\begin{tabular}{|c|c|c|c|c|c|c|}
\hline \multirow{2}{*}{\multicolumn{2}{|c|}{ Model }} & \multicolumn{2}{|c|}{$\begin{array}{c}\text { Unstandardized } \\
\text { Coefficients }\end{array}$} & \multirow{2}{*}{$\begin{array}{c}\begin{array}{c}\text { Standardized } \\
\text { Coefficients }\end{array} \\
\text { Beta }\end{array}$} & \multirow[t]{2}{*}{$\mathbf{t}$} & \multirow[t]{2}{*}{ Sig. } \\
\hline & & $\beta$ & $\begin{array}{l}\text { Std. } \\
\text { Error }\end{array}$ & & & \\
\hline \multirow[t]{2}{*}{1} & (Constant) & 3.147 & .245 & & 12.864 & .000 \\
\hline & $\begin{array}{l}\text { Adolescent } \\
\text { Friendly } \\
\text { Centre }\end{array}$ & .285 & .056 & .304 & 5.110 & .000 \\
\hline
\end{tabular}

From the results, the analysis returns $\beta$ coefficient constant of 3.147 and predictive variable of 0.285. This means that a 1-point increase on the adolescent friendly centre approach corresponds to 0.285 points increase on the delivery of ASRHS. Hence we can compute the dependent variable through the formula Dependent $=3.147+(0.285 \times$ adolescents friendly centre approach). Since all $\beta$ coefficients are positive values, it is sensible to conclude that higher values of the adolescent friendly centre approach lead to higher values of the delivery of ASRHS. The findings of the coefficients are consistent with the findings of studies reviewed under literature review that found that increased adolescent friendly centre approach leads to improved delivery of ASRHS [22]. Furthermore, all the coefficients have a significance of .000 , which is less than 0.05 , indicating that all the $\beta$ coefficients are statistically significant.

\section{DISCUSSIONS, CONCLUSIONS AND RECOMMENDATIONS}

The objective of the study was to assess the influence of adolescent friendly centre approach on delivery of adolescent sexual and reproductive health services. The analysis shows moderately weak correlation between independent variable adolescent friendly centre approach and dependent variable delivery of ASRHS with $(r>0.304$, and $p<0.01)$. This shows that the variables are statistically significant. The $\mathrm{R}$-value is 0.304 (3.04\%) which shows moderate correlation between adolescent friendly centre approach and delivery of adolescent sexual and reproductive health services. The $\mathrm{R}^{2}$ is 0.093 which means that combined independent variables account for $9.3 \%$ of the variation in the dependent variable. This means that there are other factors that account for $91.7 \%$.

Based on these findings, it is recommended that FHOK and other Non-Governmental Organizations specializing in adolescent sexual and reproductive health should strengthen the project demand creation approaches of delivery of ASRHS. It is also recommended that project this demand creation approach should be integrated in the design and delivery of health services. It is also recommended that the department of monitoring and evaluation in NonGovernmental Organizations should conduct client exit evaluations to establish the satisfaction of the adolescent sexual and reproductive health services and also consider implementation of the recommendations raised by the beneficiaries. FHOK and other NonGovernmental Organizations should also ensure that the adolescent sexual and reproductive health projects are effectively designed and implemented to assure sustainability and quality performance.

The study was delimited to the influence of adolescent friendly centre delivery approach on delivery of adolescent sexual and reproductive health services. Whereas there were statistically significant associations between project demand creation approaches and delivery of ASRHS coefficient of determination $\left(\mathrm{R}^{2)}\right.$ had lower percentages, suggesting that there were other factors other than project demand creation approaches that influence delivery of ASRHS. Based on these findings, research should be conducted to examine the influence of project design and implementation on delivery of adolescent sexual and reproductive health services in the peri-urban centres in the city. Further research should be conducted on the influence of project demand creation approaches on delivery of ASRHS in the whole country, since this study was delimited to delivery of ASRHS in three reproductive health projects.

\section{REFERENCES}

1. Madise, N. J., Ziraba, A. K., Inungu, J., Khamadi, S. A., Ezeh, A., Zulu, E. M., ... \& Mwau, M. (2012). Are slum dwellers at heightened risk of HIV infection than other urban residents? Evidence 
from population-based HIV prevalence surveys in Kenya. Health \& place, 18(5), 1144-1152.

2. Walker, D., Pereznieto, P., Bantebya, G., \& Ochen, E. (2014). Sexual exploitation of adolescent girls in Uganda: The drivers, consequences and responses to the 'sugar daddy'phenomenon. London: Overseas Development Institute.

3. Ringheim, K., \& Gribble, J. N. (2010). Improving the reproductive health of sub-Saharan Africa's youth: a route to achieve the Millennium Development Goals. Population Reference Bureau.

4. GUSÓ, A., \& LÓPEZ-QUESADA, A. (2015). ABC de Retail.

5. Kenya HIV County Profile. (2016). Published by National AIDS Control Council.

6. National Reproductive Health Policy. (2007). Ministry of Health, Republic of Kenya.

7. Mchunu, G., Peltzer, K., Tutshana, B., \& Seutlwadi, L. (2012). Adolescent pregnancy and associate factors in South African youth. Africa Health Science; 12(4):426-434.

8. Geary, R. S., Gómez-Olivé, F. X., Kahn, K., Tollman, S., \& Norris, S. A. (2014). Barriers to and facilitators of the provision of a youth-friendly health services programme in rural South Africa. BMC health services research, 14(1), 259.

9. MBBS, T. M., Kovacs, G. T., \& McDonald, P. (1998). The use of reproductive health services by young women in Australia. Australian and New Zealand journal of obstetrics and gynaecology, 38(3), 336-338.

10. Lindsay, J., Smith, A., \& Rosenthal, D. (1997). Secondary Students, HIV/AIDS and Sexual Health 1997.

11. Singh, S., \& Darroch, J. E. (2000). Adolescent pregnancy and childbearing: levels and trends in developed countries. Family planning perspectives, 14-23.

12. Ethier, K. A., Kershaw, T. S., Lewis, J. B., Milan, S., Niccolai, L. M., \& Ickovics, J. R. (2006). Selfesteem, emotional distress and sexual behavior among adolescent females: Inter-relationships and temporal effects. Journal of Adolescent health, 38(3), 268-274.

13. Fuentes. (2006). Is Limited Access to Care the New Morbidity for Latino Young Adults?

14. Jones, R. K., Purcell, A., Singh, S., \& Finer, L. B. (2005). Adolescents' reports of parental knowledge of adolescents' use of sexual health services and their reactions to mandated parental notification for prescription contraception. Jama, 293(3), 340-348.

15. Ma, J., Wang, Y., \& Stafford, R. S. (2005). US adolescents receive suboptimal preventive counseling during ambulatory care. Journal of Adolescent Health, 36(5), 441-e1.

16. https://www.guttmacher.org/sites/default/files/facts heet/adolescent-sexual-and-reproductive-health-inunited-states.pdf.
17. National Bureau of Statistics Tanzania. (2010). National bureau of statistics; Tanzania demographic health survey.

18. Pathfinder International. (2003). Youth friendly sexual and reproductive health services: An assessment of facilities.

19. Maggie, B. (2010). Falling through the cracks, adolescent girls in Tanzania. Insights from Mtwara

20. Marie Stopes International. (2012). delivering sexual and reproductive health services to young people: key lessons from Marie Stopes International's programmes.

21. Federal Ministry of Health. (2009). Assessment Report of the National Response to Young People's Sexual and Reproductive Health in Abuja, Nigeria.

22. United Nations Population Fund. (2013). State of the World's population, Motherhood in Childhood - Facing the challenges of adolescent pregnancy.

23. FHI $360 \&$ Ministry of Health Kenya. (2011). Adolescent and youth sexual and reproductive health:Taking stock in Kenya.

24. Population Council. (2011). Adolescent sexual and reproductive health conference,Nairobi,Kenya.

25. National AIDS \& STI Control Programme. (2014). Kenya AIDS Response Progress Report

26. Kenya National Bureau of Statistics (KNBS). (2015). Kenya Demographic and Health Survey 2014: Key Indicators.

27. Ministry of Education, Science and Technology. (2015). 2014 Basic Education Statistical Booklet.

28. Obare, F., Birungi, H. (2011). Levels, trends and determinants of contraceptive use among adolescent girls in Kenya: APHIA II OR Project In Kenya.Nairobi, Kenya: Population Council.

29. Njoki, M. (2015). Access to sexual and reproductive health care services by adolescent girls aged 15-19 years among pastoral communities in Narok County.

30. FHOK. (2014). available at https://www.fhok.org/fhok-documents/

31. Gray, N. J. (2007). Adolescents, the internet,and health literacy

32. Clarke, M., Dick, J., \& Lewin S. (2008). Community health workers in South Africa: where in the maze do we find ourselves? SAMJ; 98: 680_1

33. Rose, N. (2013). The Kenyan national response to internationally agreed sexual and reproductive health and right goals: a case study of three policies.

34. Gumucio, D. (2001). Stories of Participatory Communication for Social Change.

35. Marie Stopes International. (2014). Connecting with young Kenyans through comic books.

36. Schneider, H., Barron, P. (2008). Achieving the Millennium Development Goals in South Africa through the revitalisation of primary health care and a Strengthened District Health System; Position Paper; Cape Town: University of Cape Town. 
37. Warenius, L., Pettersson, K. O., Nissen, E., Höjer, B., Chishimba, P., \& Faxelid, E. (2007). Vulnerability and sexual and reproductive health among Zambian secondary school students. Culture, health \& sexuality, 9(5), 533544.

38. Motuma, J. (2012). Youth friendly services (YFS) utilization and factors in Harar, Ethiopia.

39. Bankole, A., \& Malarcher, S. (2010). Removing barriers to adolescents' access to contraceptive information and services. Studying Family Planning; 41(2):117-24

40. Hoggart, L, Phillips, J. (2011). Teenage pregnancies that end in abortion: what can they tell us about contraceptive risk taking? J Fam Plann Reprod Health Care; 37(2):97-102.

41. World Health Organization. (2014). Global status report on noncommunicable diseases 2014 (No. WHO/NMH/NVI/15.1). World Health Organization.

42. UNFPA, U. (2014). Implementation of the International and Regional Human Rights Framework for the Elimination of Female Genital Mutilation.

43. Onyando, O., Oluoch, M., \& Njuguna, S. (2018). Factors Influencing Effectiness of Youth Friendly Centres in Kenya.

44. Krejcie, R. V., \& Daryle, W. (1970). Morgan. 1970.“. Determining sample size for research activities." Educational and Psychological.
45. Orodho A. J. (2003). Essential of Education and Social Sciences Research Method. Nairobi Masola Publishers.

46. Mugenda, O. M., \& Mugenda, A. G. (2003). Research methods: Quantitative and Qualitative Approaches.Nairobi:African Centre for Technology Studies.

47. Kirby, D., Laris, B., Rolleri, L. (2005). Impact of sex and HIV education programs on sexual behaviours in developed and developing countries. Arlington (VA)

48. Mugenda, O. M., \& Mugenda A.G. (1999). Research Methods: Quantitative and Qualitative Approaches. Kenya. Acts Press.

49. Mutea, R. (2007). Fundamentals of Social Research. Signal Press Limited.

50. Mulwa, F.W. (2009). Demystifying Participatory Community Development. Paulin Publications Africa.

51. Kothari, C.R. (2004). Research Methodology: Methods and Techniques, (Second Edition), New Ag International Publishers.

52. Kombo D.K., \& Tromp L.A.D. (2006). Proposal and Theses writing: An introduction. Paulines Publication Africa.

53. Baruch, Y, \& Holtom, B.C. (2008). Survey response rate levels and trends in organizational research. 